\title{
Achalasia-microcephaly syndrome
}

INSERM

\section{Source}

INSERM. (1999). Orphanet: an online rare disease and orphan drug data base. Achalasiamicrocephaly syndrome. ORPHA:929

Achalasia-microcephaly syndrome is an extremely rare genetic syndrome, reported in a few families to date, characterized by the association of microcephaly, intellectual deficit and achalasia (with symptoms of coughing, dysphagia, vomiting, failure to thrive and aspiration appearing in infancy/early-childhood). Antenatal exposure to Mefloquine was reported in one simplex case. An autosomal recessive inheritance has been proposed. 